\title{
Changing Reasons for Visiting Primary Care Over a 35-Year Period
}

\author{
Wyatt P. Bensken, BS, Weichuan Dong, MA, Heidi Gullett, MD, MPH, \\ Rebecca S. Etz, PhD, and Kurt C. Stange, MD, PbD
}

Objective: To understand changes in reasons for visit to primary care in the face of an aging population, growing evidence for proactive preventive and chronic disease services, and the rise of the chronic care model.

Methods: We examined the reason for visits to primary care physicians using the National Ambulatory Medical Care Survey (NAMCS) from 1980-2015.

Results: Among all physicians, the percent of visits for prevention increased from 17\% in 2001 to $20 \%$ in 2015. Among visits to primary care, most continued to be for acute problems - with the percent of visits for acute illness declining over the past 15 years, after remaining steady for two decades. Preventive care visits increased from 19\% in 2001 to $26 \%$ in 2015 . The percent of primary care visits for chronic conditions declined between 1980 and 2000, and then remained steady, accounting for $30 \%$ in 2001 and $31 \%$ in 2015.

Conclusions: Growing emphasis on chronic disease management is not reflected in the percent of primary care visits for chronic illness. This study highlights the potential utility of longitudinal data within a historical interpretive frame, while raising questions about the utility of using a main reason for visit to classify complex primary care visits. (J Am Board Fam Med 2021;34:442-448.)

Keywords: Chronic Disease, Delivery of Health Care, Disease Management, Preventive Health Services, Primary Care Physicians, Primary Health Care

\section{Introduction}

Recent decades have seen dramatic changes in the practice of medicine. ${ }^{1-6}$ These changes have been fomented by forces within and outside of health care and many other factors, including response to an aging population, a growing burden of behaviorally mediated and chronic illness, expanding technology, a changing health care workforce, ongoing

This article was externally peer reviewed.

Submitted 13 April 2020; revised 28 July 2020; accepted 29 July 2020.

From the Department of Population and Quantitative Health Sciences, School of Medicine, Case Western Reserve University, Cleveland, OH (WPB, WD, KCS); Center for Community Health Integration, School of Medicine, Case Western Reserve University, Cleveland, OH (HG, KCS); Department of Family Medicine and Population Health, Virginia Commonwealth University, Richmond (RSE).

Funding: None.

Conflicts of interest: None declared.

Corresponding author: Wyatt P. Bensken, BS, Doctoral Student, Department of Population and Quantitative Health Sciences, School of Medicine, Case Western Reserve University, 10900 Euclid Ave, WG-43, Cleveland, OH 44106 (E-mail: wpb27@case.edu). cost increases, and reforms in the organization and payment for care.

During the past 3 decades, the US Preventive Services Task Force ${ }^{7,8}$ has systematically provided evidence of the effectiveness of preventive services, and the chronic care model ${ }^{9-11}$ has assumed prominence in policy and practice circles by calling attention to the rising rates and costs of caring for people with chronic conditions. The past decade has seen growing recognition of the rise in multimorbidity-people living with multiple chronic conditions, ${ }^{12-14}$ which constitute the majority of visits by adults to primary care. ${ }^{15}$

The frontline for these health care changes is primary care, which accounts for about half of all outpatient visits, ${ }^{16}$ and which has been the target of some of the most intensive reform efforts, most notably the patient-centered medical home ${ }^{17-19}$ but also other payment and practice reform efforts. ${ }^{20-22}$ Concomitant changes toward an employed physician workforce and growing use of urgent care centers and emergency departments also influence care. 
Despite all this change, there has been little longitudinal study of changes in practice over time. ${ }^{23}$ Therefore, we undertook this study to examine the changes in the major reason for visit to primary care during a 35-year period using the nationally representative National Ambulatory Medical Care Survey (NAMCS), for which reason for visit data have been available since 1980. We hypothesized that we would see a growing percentage of visits for chronic illness and a concomitant reduction in the percentage of visits for acute illness.

\section{Methods}

Data from the NAMCS were obtained via the public domain of the National Center for Health Statistics (NCHS) at the Centers for Disease Control and Prevention (CDC) (https://www.cdc. gov/nchs/ahcd/ahcd_questionnaires.htm) and the Interuniversity Consortium for Political and Social Research (ICPSR) (https://www.icpsr.umich.edu/ icpsrweb/). NAMCS was not administered in 1974, 1982 to 1983 , and 1986 to 1988 , and reason for visit was not collected in 1977 and 1985 to 1996 . For these reasons, data points pre-2000 were limited but were included to use all available data. NAMCS is a long-running survey of ambulatory care visits in the United States that uses a multistage probability design to capture information about a representative sample of clinical encounters. ${ }^{24-27}$ These samples are then weighted to establish national estimates and were weighted within each year using the provided weighting information.

Our primary analyses were focused on major reason for visit, a categorical variable coded from information reported during the visit. Due to variable changes over the years, we made a number of decisions in an effort to provide measures that as consistently as possible assess the same construct over time. For the chronic disease category, we merged flare-up and routine chronic visits, which exhibited similar trends. For the acute visit category, the following variables were combined across years: acute problem (1980, 1981, 1997, 2000 to 2004), new problem (2005 to 2006), new problem (less than 3 months) (2007 to 2015). A preventive visit category became available in 2001 . These decisions were made after multiple visualizations of the variable availability and rates across the years.

To provide additional context for interpreting changes in the major reason for visit, we also analyzed a more granular categorical variable reflecting more detailed reasons for visit: 2 preventive categories (general examination and well-baby examination) and 2 common chronic conditions (diabetes mellitus and hypertension). ${ }^{28,29}$

Our main analyses grouped visits to general practitioners, family physicians, general internists, and general pediatricians. To provide additional context, we examined data for all physicians together and then for each of the 4 primary care specialties separately. To assess if specialists have been seeing more chronic conditions in recent years, we evaluated reason for visit in a subset of specialists available in NAMCS, excluding primary care and all surgical specialties. Although the exact language and specialists captured varied from year to year, they included allergy, cardiology, dermatology, endocrinology, gastroenterology, gynecology, hematology, nephrology, neurology, obstetrics/gynecology, occupational medicine, oncology, ophthalmology, other, otolaryngology, otorhinolaryngology, physical medicine, psychiatry, public health pulmonary, and urology.

Data cleaning and weighting were conducted via SAS version 9, specifically using the PROC SURVEYFREQ procedure with the included strata, cluster, and weights to account for the complex survey design. All main analyses followed proper procedures and ensured adequate sample size for weighting. Data visualization was conducted via $\mathrm{R}$ version 3.6.0, using the "tidyverse" package, to depict the percentage of visits in each category over time. For the early years in which NAMCS was not administered every year (1975 to 2000), we conducted analyses at 5-year intervals or during years when data were available. Beginning in 2000, we analyzed data for each year.

\section{Results}

In the years 1980, 1981, 1997, and 2000 through 2015 , a national total of $16,935,413,908$ visits to ambulatory care providers were estimated to have occurred, based on a sample of 661,327 visits reported in NAMCS. Of these, visits to primary care (defined as family medicine, internal medicine, general practice, and pediatrics) represented 256,068 visits weighted to a national total of 8,580,957,687.

Among all specialties together, as shown in Figure 1, visits for chronic illness are most common and account for a higher percentage of visits since 2000. The percentage of all visits that were for 
Figure 1. Major reason for visit, all.

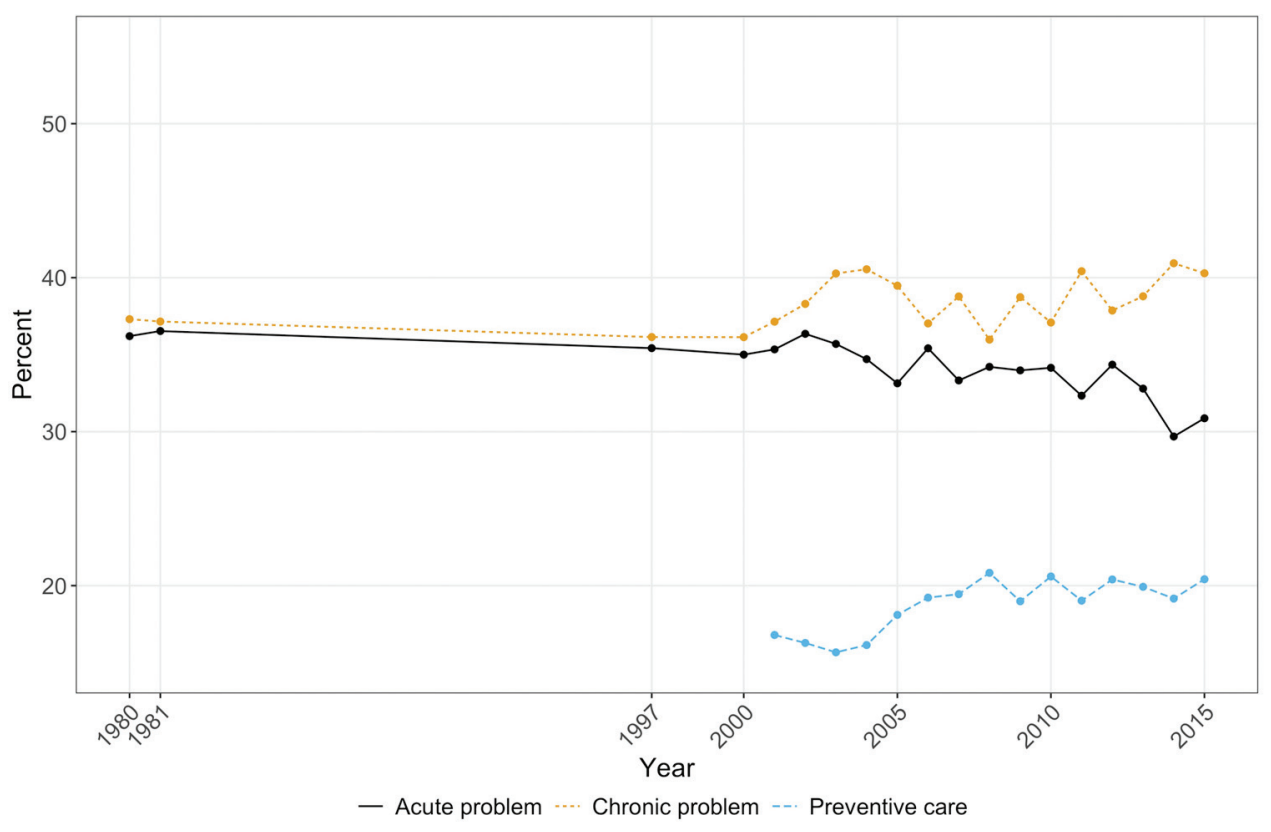

acute illness has declined since 2000, and the percentage of visits for prevention has gone up.

Within primary care (Figure 2), acute illness visits account for the majority of visits and have declined during the past decade. Visits for chronic illness have declined slightly over 35 years, with a small rise 2000 to 2005 , then declining to the 2000 base and remaining fairly steady through 2015 . Visits for prevention, assessed only since 2001, have been increasing steadily since 2003. Parallel to these changes in primary care, among specialists we saw an overall increase the percentage of visits for chronic illness (Figure 3).

Of the selected more granular reasons for visit, the most striking change over time is the sharp increase in the proportion of visits for general medical examination, amid stable rates for well-baby care and for the 2 chronic conditions examined (Figure 4).

\section{Discussion}

We expected to see a large rise in the percentage of visits for chronic illness, due to the aging of the population, the growing burden of chronic disease, ${ }^{30,31}$ and the rising prominence of the chronic care model. ${ }^{9-11,32}$ Instead, we observed an increase in the percentage of visits for preventive service delivery. We saw a slight increase in the percentage of visits for chronic illness among all specialties together and a slight decline followed by relative stability since 2000 in primary care. In the past decade, the percentage of visits for acute illness has declined for all specialties together and for primary care.

The rise in the percentage of visits for preventive service delivery may reflect the growing evidence for effective clinical preventive services, the rising prominence of the US Preventive Services Task Force, ${ }^{7,8}$ and the incorporation of its recommended services in insurance plans.

The surprising lack of increase in the percentage of visits for chronic illness, particularly in primary care where recent reforms emphasize proactive chronic disease care through management programs that aim to reduce visits for these chronic diseases, may reflect the offloading of some of this care to chronic disease management programs not captured in physician visit data. ${ }^{33-37}$ Despite the growing emphasis on chronic disease management in primary care, it is interesting that the most common reason for visit in primary care is acute illness and across all specialties is chronic illness. The decline in the percentage of visits for acute illness also may reflect growing use of urgent care centers, emergency departments, and telehealth.

During the past 35 years, there has been an expansion in specialty care. ${ }^{38}$ The rise in the percentage of 
Figure 2. Major reason for visit, primary care.

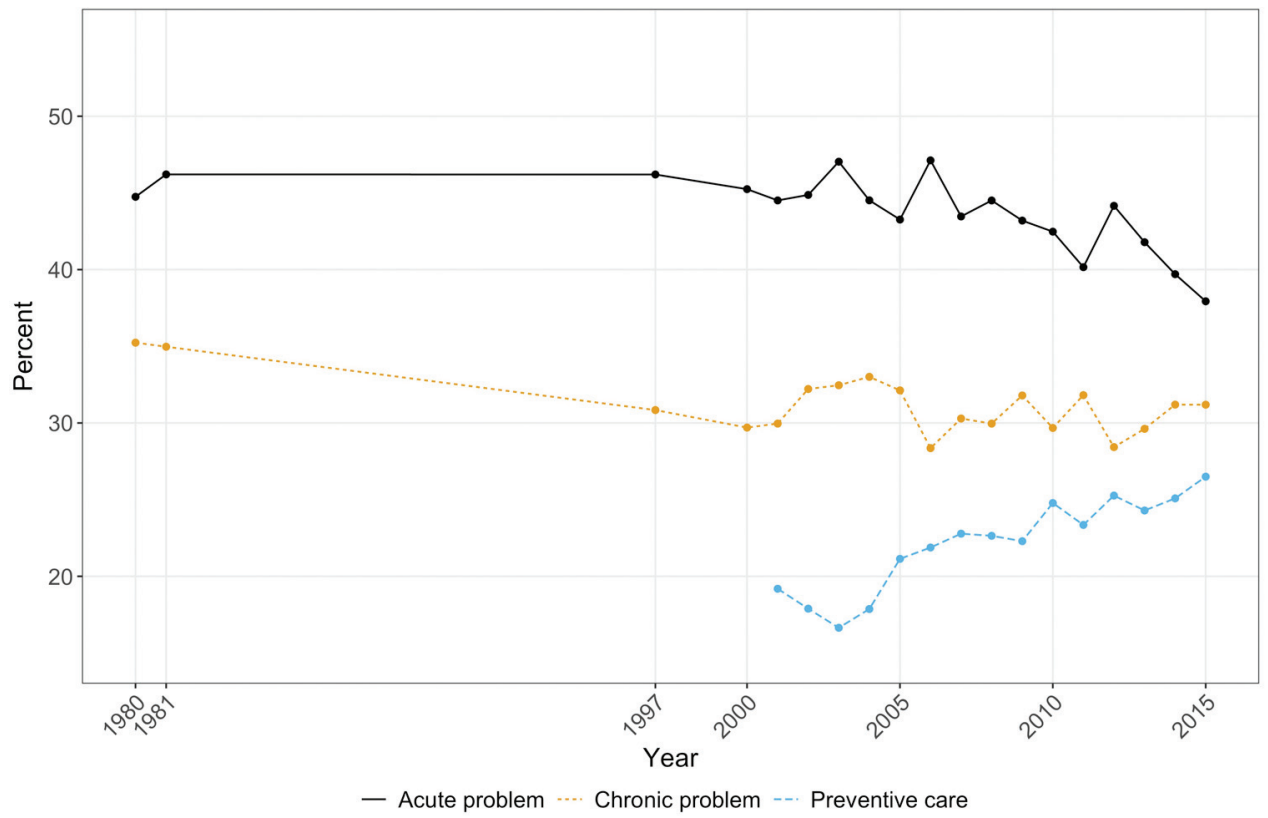

Figure 3. Major reason for visit, specialists.

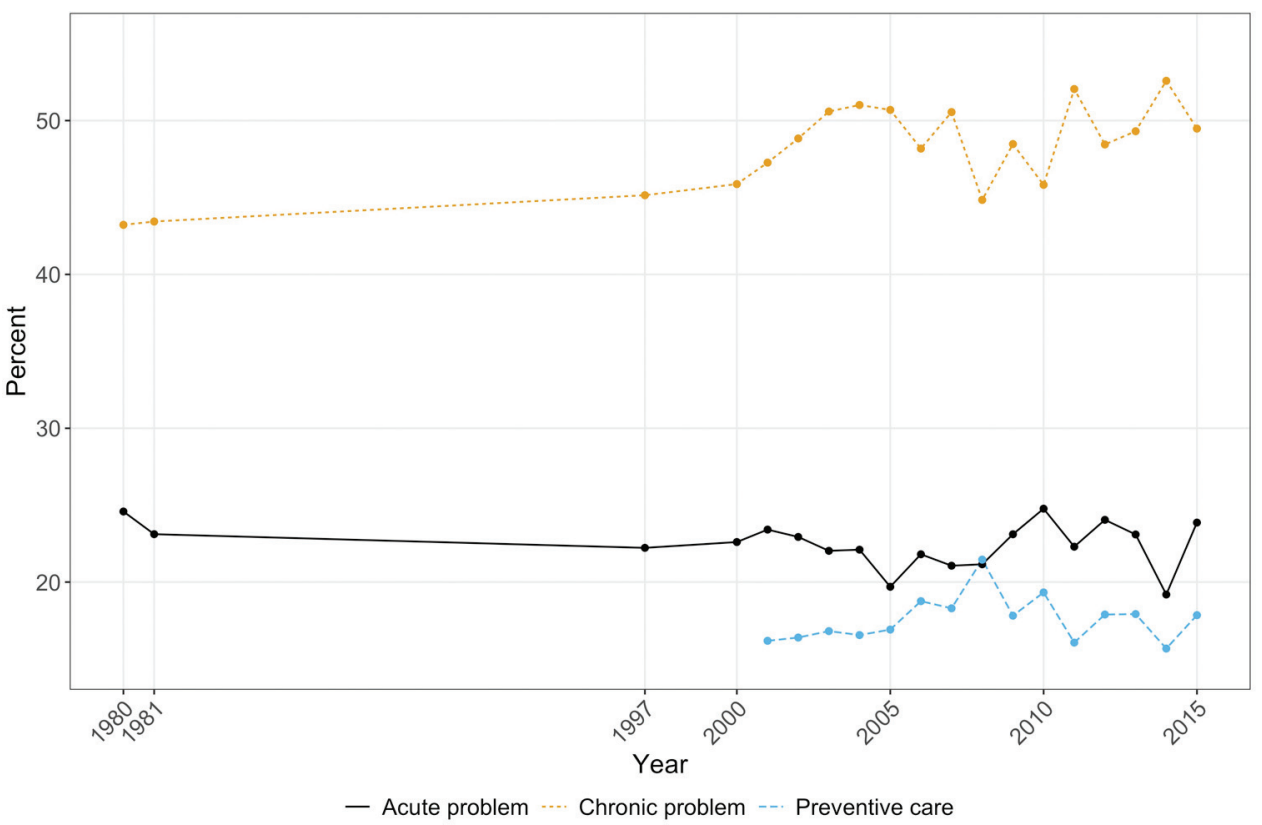

visits for chronic disease among all physicians may be an indication that a growing percentage of chronic illness is managed in specialty care. ${ }^{38-41}$ This may be problematic, given the growing rates of people living with multiple chronic conditions for whom a medical home that integrates care is important. ${ }^{42}$ The growth of specialty and subspecialty fields combined with the fluctuation of primary care workforce suggests that conditions that perhaps were handled solely by primary care physicians are now being referred out and managed by specialists. ${ }^{43,44}$ Although we were unable to fully confirm this hypothesis, in evaluating the reason for visit among specialists included in the NAMCS, we did observe an increase in reason for 


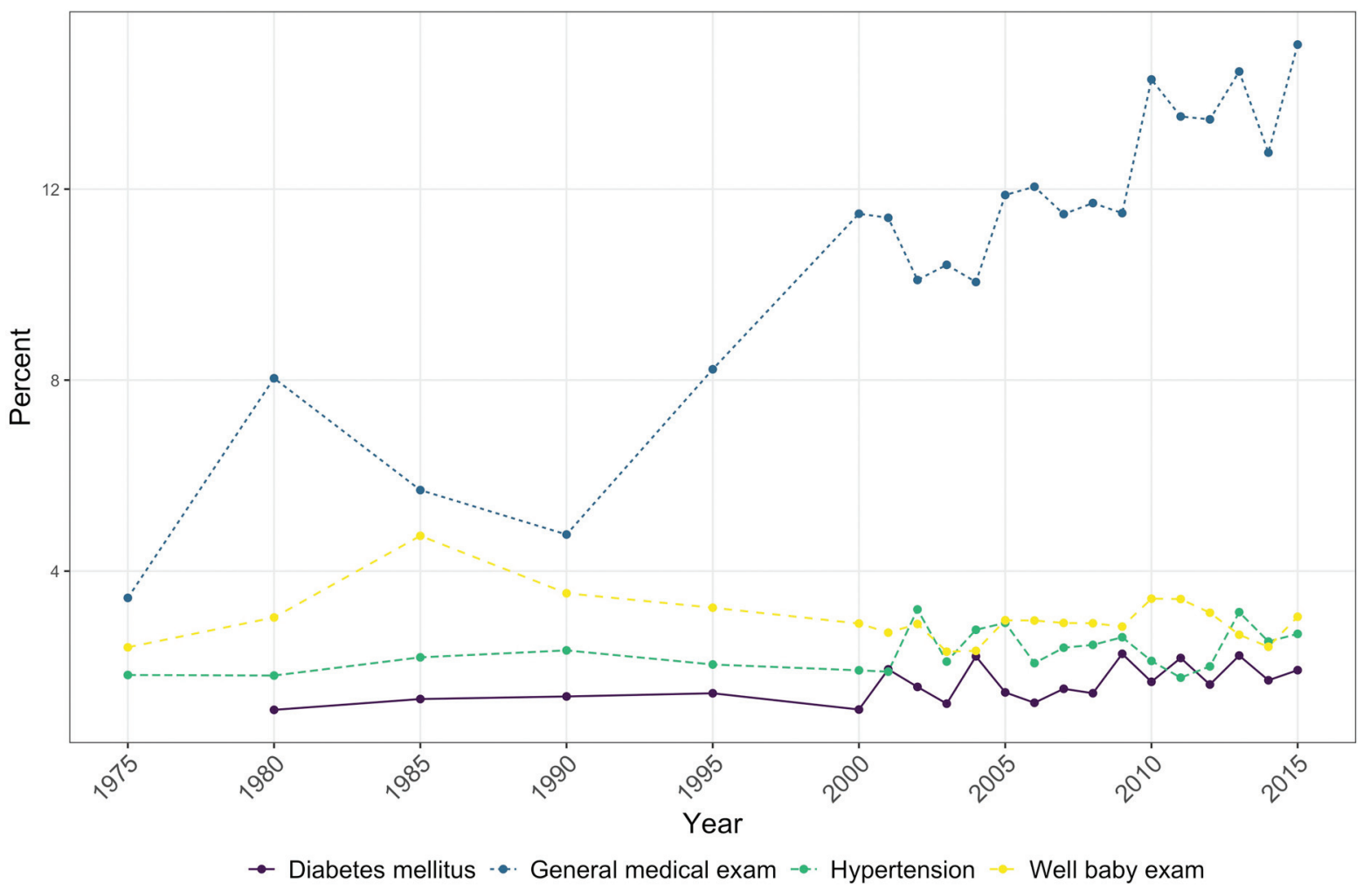

visit being chronic condition, suggesting that this is a plausible explanation (Figure 3).

This study underscores the potential utility and challenges of using the longitudinal NAMCS data to assess broad changes in care delivery. The utility relates to the ability to examine trends in nationally representative data whose sampling method has remained reasonably consistent over multiple decades of immense change in US health care. The challenges relate to changes in the wording of questions that limit the ability to examine trends.

The findings also raise concerns about how well common reason for visit classifications fit with the many problems and opportunities addressed in primary care practice and how sensitive the reason for visit categories are to changes in practice. As the chronic disease burden in the United States has increased, it is plausible that these become a routine part of the visit and are not reported by the physician as the major reason for visit. ${ }^{45}$ This is supported by the observed steady rates of visits where the primary reason was diabetes and hypertension, as we would expect these rates to rise otherwise (Figure 4).

The physician-report measure used in NAMCS has shown generally good concordance with direct observation, but over-reporting of visit duration and under-reporting of behavioral counseling shows the potential for inaccuracy in physician report using the NAMCS form. ${ }^{46}$ There are many factors that may affect physicians' judgment of what to indicate as the major reason for visit in the NAMCS survey. Certainly, what is paid for and therefore incentivized to be coded for billing purposes likely changed what care is salient to physicians over time. We also do not want to underestimate the cognitive challenge of coming up with a major reason for visit when multimorbidity has been found to be the norm in primary care visits, ${ }^{15}$ and when the number of problems addressed during a primary care visit has been found to be 2 to 3 based on billing data for the average visit, ${ }^{47,48} 5$ to 6 for visits by diabetic patients, ${ }^{49}$ and by a more sensitive direct observation measure, 25 problems addressed during the average diabetes follow-up visit at a highfunctioning community health center. ${ }^{50}$

The findings of this study both highlight changes in reason for visit during the past 35 years and raise questions about the utility of using a physician-reported reason for visit to classify increasingly complex visits. Future work should follow these findings to further assess the changes and 
evolution of primary care over the years, while concurrently develop methodology that can be used prospectively to more accurately reflect the complexity of care.

The authors would like to thank Dr. William L. Miller and Dr. Siran M. Koroukian for their support and assistance through the project, including interpreting initial data and findings.

To see this article online, please go to: http://jabfm.org/content/ 34/2/442.full.

\section{References}

1. Guerin S. Managing rapid change in the health care environment. Manag Care 2013;22:44-6.

2. Loxterkamp D. A change will do you good. Ann Fam Med 2009;7:261-3.

3. DeVoe J. The unsustainable US health care system: a blueprint for change. Ann Fam Med 2008;6:263-6.

4. Freed GL, Nahra TA, Wheeler JR. Which physicians are providing health care to America's children? Trends and changes during the past 20 years. Arch Pediatr Adolesc Med 2004;158:22-6.

5. Mostashari F, Sanghavi D, McClellan M. Health reform and physician-led accountable care: the paradox of primary care physician leadership. JAMA 2014;311:1855-6.

6. Rittenhouse DR, Shortell SM. The patient-centered medical home: will it stand the test of health reform? JAMA 2009;301:2038-40.

7. Lawrence RS, Mickalide AD, Kamerow DB, Woolf SH. Report of the U.S. Preventive Services Task Force. JAMA 1990;263:436-7.

8. Lawrence RS. Diffusion of the U.S. Preventive Services Task Force recommendations into practice. J Gen Intern Med 1990;5:S99-S103 (Suppl).

9. Coleman K, Austin BT, Brach C, Wagner EH. Evidence on the chronic care model in the new millennium. Health Aff (Millwood) 2009;28:7585.

10. Glasgow RE, Orleans CT, Wagner EH. Does the chronic care model serve also as a template for improving prevention? Milbank Q 2001;79:579-612.

11. Wagner EH, Austin BT, Von Korff M. Organizing care for patients with chronic illness. Milbank Q 1996;74:511-44.

12. Bayliss EA, Bonds DE, Boyd CM, et al. Understanding the context of health for persons with multiple chronic conditions: moving from what is the matter to what matters. Ann Fam Med 2014;12:260-9.

13. Ward BW, Schiller JS. Prevalence of multiple chronic conditions among US adults: estimates from the National Health Interview Survey. Prev Chronic Dis 2013;10:E65.
14. Ashman JJ, Beresovsky V. Multiple chronic conditions among US adults who visited physician offices: data from the National Ambulatory Medical Care Survey, 2009. Prev Chronic Dis 2013;10:E64.

15. Fortin M, Bravo G, Hudon C, Vanasse A, Lapointe L. Prevalence of multimorbidity among adults seen in family practice. Ann Fam Med 2005;3:223-8.

16. Peabody MR, Neill TR, Stelter KL, Puffer JC. Frequency and criticality of diagnoses in family medicine practices: from the National Ambulatory Medical Care Survey (NAMCS). J Am Board Fam Med 2018;31:126-38.

17. Jackson GL, Powers BJ, Chatterjee R, et al. The patient-centered medical home: a systematic review. Ann Intern Med 2013;158:169-78.

18. Nutting PA, Crabtree BF, Miller WL, Stange KC, Stewart E, Jaén C. Transforming physician practices to patient-centered medical homes: lessons from the national demonstration project. Health Aff (Millwood) 2011;30:439-45.

19. Stange KC, Nutting PA, Miller WL, et al. Defining and measuring the patient-centered medical home. J Gen Intern Med 2010;25:601-12.

20. Rittenhouse DR, Shortell SM, Fisher ES. Primary care and accountable care- two essential elements of delivery-system reform. N Engl J Med 2009;361: 2301-3.

21. Bodenheimer T, Ghorob A, Gupta R, Willard R, Wong J. The 10 building blocks of high-performing primary care. Ann Fam Med 2014;166-71.

22. Bodenheimer T, Pham HH. Primary care: current problems and proposed solutions. Health Aff (Millwood) 2010;29:799-805.

23. Rao A, Shi Z, Ray KN, Mehrotra A, Ganguli I. National trends in primary care visit use and practice capabilities, 2008-2015. Ann Fam Med 2019; 17:538-44.

24. Tenney JB, White KL, Williamson JW. National Ambulatory Medical Care Survey: Background and Methodology. Rockville, MD; 1974.

25. Bryant EE, Shimizu I. Sample design, sampling variance and estimation procedures for the National Ambulatory Medical Care Survey. Hyattsville, MD: National Center for Health Statistics; 1988.

26. National Center for Health Statistics. About the Ambulatory Health Care Surveys. Centers for Disease Control and Prevention. 2019. Available from: https://www.cdc.gov/nchs/ahcd/about_ahcd. htm. Accessed September 19, 2019.

27. National Center for Health Statistics. NAMCS scope and sample design. Centers for Disease Control and Prevention. 2015. Available from: https://www.cdc. gov/nchs/ahcd/ahcd_scope.htm. Accessed September 16, 2019.

28. National Center for Health Statistics. Survey content for the National Ambulatory Medical Care Survey 
and National Hospital Ambulatory Medical Care Survey. National Center for Health Statistics; 2012.

29. Schneider D, Appleton L, McLemore T. A reason for visit classification for ambulatory care. Vital Health Stat 2 1979;78:1-630.

30. Wagner EH. Organizing care for patients with chronic illness revisited. Milbank Quarterly. 2019;97:659-64.

31. Koroukian SM, Schiltz N, Warner DF, et al. Combinations of chronic conditions, functional limitations, and geriatric syndromes that predict health outcomes. J Gen Intern Med 2016;31:630-7.

32. Berwick DM. Reflections on the chronic care model-23 years later. Milbank Quarterly 2019. Available from: https://www.milbank.org/quarterly/ articles/reflections-on-the-chronic-care-model-23years-later/. Accessed September 11, 2019.

33. DeHaven MJ. Multimorbidity, chronic disease, and community health science. J Eval Clin Pract 2017;23:219-21.

34. Scott IA. Chronic disease management: a primer for physicians. Intern Med J 2008;38:427-37.

35. Krause DS. Economic effectiveness of disease management programs: a meta-analysis. Dis Manag 2005;8:114-34.

36. Ofman JJ, Badamgarav E, Henning JM, et al. Does disease management improve clinical and economic outcomes in patients with chronic diseases? A systematic review. Am J Med 2004;117:182-92.

37. Department of Health. Chronic disease management: a compendium. 2004. Available from: http:// www.natpact.nhs.uk/uploads/Chronic\%20Care\%20 Compendium.pdf. Accessed July 13, 2010.

38. Valderas JM, Starfield B, Forrest CB, Sibbald B, Roland M. Ambulatory care provided by officebased specialists in the United States. Ann Fam Med 2009;7:104-11.

39. Starfield B, Fryer GE, Jr. The primary care physician workforce: ethical and policy implications. Ann Fam Med 2007;5:486-91.

40. Starfield B, Lemke KW, Herbert R, Pavlovich WD, Anderson G. Comorbidity and the use of primary care and specialist care in the elderly. Ann Fam Med 2005;3:215-22.

41. Starfield B, Lemke KW, Bernhardt T, Foldes SS, Forrest CB, Weiner JP. Comorbidity: implications for the importance of primary care in "case" management. Ann Fam Med 2003;1:8-14.

42. Poitras ME, Maltais ME, Bestard-Denomme L, Stewart M, Fortin M. What are the effective elements in patient-centered and multimorbidity care? A scoping review. BMC Health Serv Res 2018;18:446.

43. Muhlestein D, Winfield L. Preparing a new generation of physicians for a new kind of health care. $\mathrm{N}$ Engl J Med Catalyst 2018.

44. Dalen JE, Ryan KJ, Alpert JS. Where have the generalists gone? They became specialists, then subspecialists. Am J Med 2017;130:766-8.

45. Bodenheimer T, Chen E, Bennett HD. Confronting the growing burden of chronic disease: can the U.S. health care workforce do the job? Health Aff (Millwood) 2009;28:64-74.

46. Gilchrist VJ, Stange KC, McCord G, Bourget CC, Flocke SA. A comparison of the National Ambulatory Medical Care Survey (NAMCS) measurement approach with direct observation of outpatient visits. Med Care 2004;42:276-80.

47. Flocke SA, Frank SH, Wenger DA. Addressing multiple problems in the family medicine office visit. J Fam Pract 2001;50:211-6.

48. Stange KC, Zyzanski SJ, Jaen CR, et al. Illuminating the black box: a description of 4454 patient visits to 138 family doctors. J Fam Pract 1998;46:377-89.

49. Beasley JW, Hankey TH, Erickson R, et al. How many problems do family physicians manage at each encounter? A WReN study. Ann Fam Med 2004;2:405-10.

50. Bolen SD, Sage P, Perzynski AT, Stange KC. No moment wasted: the primary-care visit for adults with diabetes and low socio-economic status. Prim Health Care Res Dev 2016;17:18-32. 